\title{
Different Central Localizations, Different Histopathologies, Benefits, and Side Effects of Radiotherapy in Neurocytoma
}

\author{
Kamuran İBiş, ${ }^{1}$ Rasim MERAL, ${ }^{1}$ Ahmet KARAdENiZ, ${ }^{1}$ Murat GÜVELi, ${ }^{1}$ \\ Selnur ÖZKURT, ${ }^{2}$ Bilge BiLGiç, ${ }^{3}$ Musa ALTUN' ${ }^{1}$ \\ 'Department of Radiation Oncology, İstanbul University, Institute of Oncology, İstanbul-Turkey \\ ${ }^{2}$ Department of Radiation Oncology, Balıkesir State Hospital, Balikesir-Turkey \\ ${ }^{3}$ Department of Pathology, İstanbul University, Institute of Oncology, İstanbul-Turkey
}

\begin{abstract}
OBJECTIVE
Neurocytoma is a rare tumor of central nervous system (CNS). The present study is an analysis of benefits and risks of radiotherapy (RT) after surgery.

\section{METHODS}

Following a retrospective evaluation of 2186 CNS tumors treated at the university oncology institute, 6 cases of neurocytoma were found. These 6 cases were analyzed according to patient sex, age, location of tumor, treatment type, and survival.

\section{RESULTS}

Median patient age was 40 years. Four tumors were centrally located, and the remaining 2 tumors were located in the extraventricular region. All of the patients received 50-60 Gy of conventional irradiation. Median length of follow-up was 51 months (range: 15-88 months). In this study, 5-year survival rate was $60 \%$.
\end{abstract}

\section{CONCLUSION}

Primary treatment for neurocytoma is surgery. RT is suggested only for subtotally resected tumors, recurrent tumors, or tumors with atypical characteristics due to delayed side effects.

Keywords: Central neurocytoma; neurosurgery; radiotherapy; stereotactic radiosurgery.

Copyright $\odot$ 2016, Turkish Society for Radiation Oncology

\section{Introduction}

Neurocytoma was first described by Hassoun et al.[1] in 1982. It is a rare brain tumor characterized by typical ultrastructural neuronal differentiation and immunohistochemical profile. Neurocytoma comprises approximately $1 \%$ of all brain tumors. It is most often seen in young adults, with obvious peaks in second and third decades of life.[2-5] Neurocytoma is described as a benign grade II tumor by World Health Organization (WHO). It is typically located deep midline or even in supratentorial region, as well as in septum pellicidum, fornices, or lateral ventricles. [2,3,5,6] Symptoms due to increased intracranial pressure and obstructive hydrocephalus are generally present. Symptoms such as headache, nausea, vomiting, and visual disturbances are seen in the last few months. [2,3,5,7]

Neurocytoma is differentiated into 2 main subgroups: Typical neurocytomas account for $75 \%$ (benign lesion with high grade cellular differentiation and low mitotic activity), and atypical neurocytomas make 
up 25\%.[2,5,8] Atypical neurocytoma is characterized by MIB-1 labeling index $>2-3 \%$, necrosis, increased mitotic activity, and vascular proliferation. [4,9] Neurocytoma shares some histopathological similarities with oligodendroglioma and ependimoma, which has historically resulted in diagnostic errors.[4,10] Definitive diagnosis is sine qua non because prognosis for neurocytoma is generally good and total surgical resection is almost always curative. Nevertheless, atypical histological features or centrally located atypical neurocytomas with high-grade mitotic activity are associated with high recurrence rates and unfavorable prognosis. $[11,12]$ Whereas typical features of extraventricular neurocytomas are similar, they have obviously worse prognosis that requires adjuvant therapies. $[13,14]$

Primary treatment of neurocytoma is total surgical excision if possible. Radiotherapy (RT) is used to prevent recurrence or for salvage therapy. $[15,16]$ Several studies have shown that there is no need for RT after total resection of neurocytoma. $[11,17]$ This study evaluated a small series of neurocytoma patients who received $\mathrm{RT}$ in the last 27 years due to residual tumor, inoperability of the tumor or atypical neurocytoma features.

\section{Materials and Methods}

Retrospective evaluation of a series of 2186 patients (>18 years old) with central nervous system (CNS) tumor treated at Institute of Oncology, Istanbul University, between January 1987 and December 2014 revealed 6 patients diagnosed with neurocytoma. Data about patient age, sex, symptoms, duration of symptoms, Karnofsky Performance Status (KPS) at admission, tumor localization, tumor size, surgical resection type (biopsy, subtotal resection [STR], gross total resection [GTR]), histopathological examination details, RT dosage, irradiation technique, recurrent disease, progression of disease, and final status of the patient were retrospectively analyzed.
Overall survival was calculated using Kaplan-Meier test. For 5 patients, the period between surgery and death was used, while for the last patient, who was stereotactically biopsied, the period between biopsy and death was used.

\section{Results}

There were 2 (33.3\%) female patients and 4 (66.7\%) male patients with a median age of 40 years (range: 23-44 years). Among the 4 (66.7\%) patients with central (ventricular) neurocytoma, 2 (33.3\%) were located in the third ventricle, 1 in the fourth ventricle, and 1 in the left lateral ventricle. In 2 (33.3\%) patients with extraventricular neurocytoma, 1 tumor was located in corpus callosum and the other was in right frontal lobe (Table 1). One patient was diagnosed with hydrocephalus at admission, but shunt procedure was not required. The most common symptoms at admission were headache (50\%) and nausea/vomiting (50\%). The remaining symptoms were loss of consciousness, weakness of lower extremities, generalized seizure, and loss of balance. Median duration of symptoms was 4 weeks (range: 0-3 weeks). Preoperative median KPS was 95 (40-100). All of the patients were scanned with magnetic resonance imaging (MRI) pre- and postoperatively. While 5 patients had undergone surgical resection, 1 patient with an extraventricular neurocytoma located in corpus callosum was biopsied using only stereotactic technique. Median maximum tumor size was $3 \mathrm{~cm}$ (range: $2.4-4$ $\mathrm{cm})$. STR was applied to $4(80 \%)$ of the 5 patients, and the remaining patient (20\%) received GTR. Residual tumor size was $1 \mathrm{~cm}$.

Immunohistopathological evaluation of tumors revealed $6(100 \%)$ synaptophysin- positive stained tumors, and 3 (50\%) tumors positive in places for glial fibrillary acidic protein (GFAP). For differential diagnosis of ependymoma in $2(33.3 \%)$ of the patients, epi-

\begin{tabular}{|c|c|c|c|c|c|c|c|}
\hline $\begin{array}{l}\text { Patient } \\
\text { No }\end{array}$ & $\begin{array}{l}\text { Age } \\
\text { (years) }\end{array}$ & Gender & $\begin{array}{c}\text { Tumor } \\
\text { localization }\end{array}$ & $\begin{array}{c}\text { Histopathological } \\
\text { definition }\end{array}$ & Treatment & $\begin{array}{l}\text { RT Dose } \\
\text { (Gy/fr) }\end{array}$ & Follow-up \\
\hline 1 & 27 & Male & Central & Atypical & GTR+RT & $60 \mathrm{~Gy} / 30 \mathrm{fr}$ & Lost to Follow-up \\
\hline 2 & 44 & Male & Extraventricular & Typical & Biopsy+RT & $60 \mathrm{~Gy} / 30 \mathrm{fr}$ & Dead \\
\hline 3 & 42 & Male & Central & Atypical & $\mathrm{GTR}+\mathrm{RT}$ & $50 \mathrm{~Gy} / 25 \mathrm{fr}$ & Dead \\
\hline 4 & 38 & Male & Extraventricular & Atypical & $\mathrm{GTR}+\mathrm{RT}$ & $54 \mathrm{~Gy} / 27 \mathrm{fr}$ & Alive \\
\hline 5 & 42 & Female & Central & Atypical & $\mathrm{GTR}+\mathrm{RT}$ & $60 \mathrm{~Gy} / 30 \mathrm{fr}$ & Dead \\
\hline 6 & 23 & Female & Central & Typical & $\mathrm{STR}+\mathrm{RT}$ & $58 \mathrm{~Gy} / 29 \mathrm{fr}$ & Alive \\
\hline
\end{tabular}

RT: Radiotherapy; Gy: Gray; GTR: Gross total resection; STR: Subtotal resection. 
thelial membrane antigen (EMA) stain was negatively tested; it was not necessary in the remaining 4 cases in the series. Neurofilament protein (NFP) stain was positive in $1(16.7 \%)$ patient and negative in $3(50 \%)$ patients. Necrosis was detected in $2(33.3 \%)$ patients and high mitotic rate was detected in 1 (16.7\%). In half of the patients, the MIB-1 labeling index was $<3 \%$, and it was $>3 \%$ in the other half (Figure 1). According to these histopathological characteristics, 4 (66.7\%) of the tumors were diagnosed as atypical neurocytoma, and the remaining 2 (33.3\%) were diagnosed as typical neurocytoma. Patients received total dose of 50-60 Gy with $200 \mathrm{cGy} /$ fractions. Three (50\%) patients received 2-dimensional (2D) Cobalt-60 (Co-60) radiation and the other $3(50 \%)$ patients received 3-dimensional (3D) conformal RT with linear accelerator.

Patient with neurocytoma in corpus callosum who was biopsied survived for 42 months. Patient with atypical neurocytoma who was irradiated with $50 \mathrm{~Gy} / 25 \mathrm{fr}$ after surgery died 31 months after initial treatment, despite $5 \times 6$ Gy stereotactic irradiation, due to inoperable intraventricular recurrence 2 months after diagnosis.

Patient with atypical neurocytoma located in fourth ventricle underwent surgery 43 months after initial operation due to $4 \mathrm{~cm}$-sized lesion in occipitotemporal area that was only a necrotic lesion following irradiation. Patient developed hydrocephalus 1 month after the last surgery, necessitating a ventriculoperitoneal shunt; however, general condition of the patient continued to deteriorate. Patient developed amnesia, walking and speech disturbances and died 6 months after secondary surgery despite 8 cures of bevacizumab (vascular endothelial growth factor [VEGF] monoclonal antibody; $7.5 \mathrm{~g} / \mathrm{kg}$ once every 2 weeks).

Three patients ( 2 with atypical central neurocytoma after surgical intervention and 1 with extraventricular neurocytoma without surgery) died. One patient with atypical neurocytoma was disease-free in the $15^{\text {th }}$ postoperative month but was subsequently lost to followup. Two patients were disease-free (1 patient with atypical extraventricular neurocytoma, and 1 with typical neurocytoma that was subtotally resected). In the present series, median follow-up was 51 months (range: 15-88 months) and the 5-year survival rate.

\section{Discussion}

Central neurocytoma was first described by Hassoun et al.[1] in 1982. An electron microscope was used to present detailed neural characteristics of 2 extraventricular tumors. The name central neurocytoma was given due to median location within ventricle and neural origin. Extraventricular neurocytoma is located periventricularly or parenchymally.[18] Extraventricular neurocytoma is generally associated with worse outcome than central neurocytoma.[19] Consequently, it is listed as a separate diagnosis in the last WHO clas-
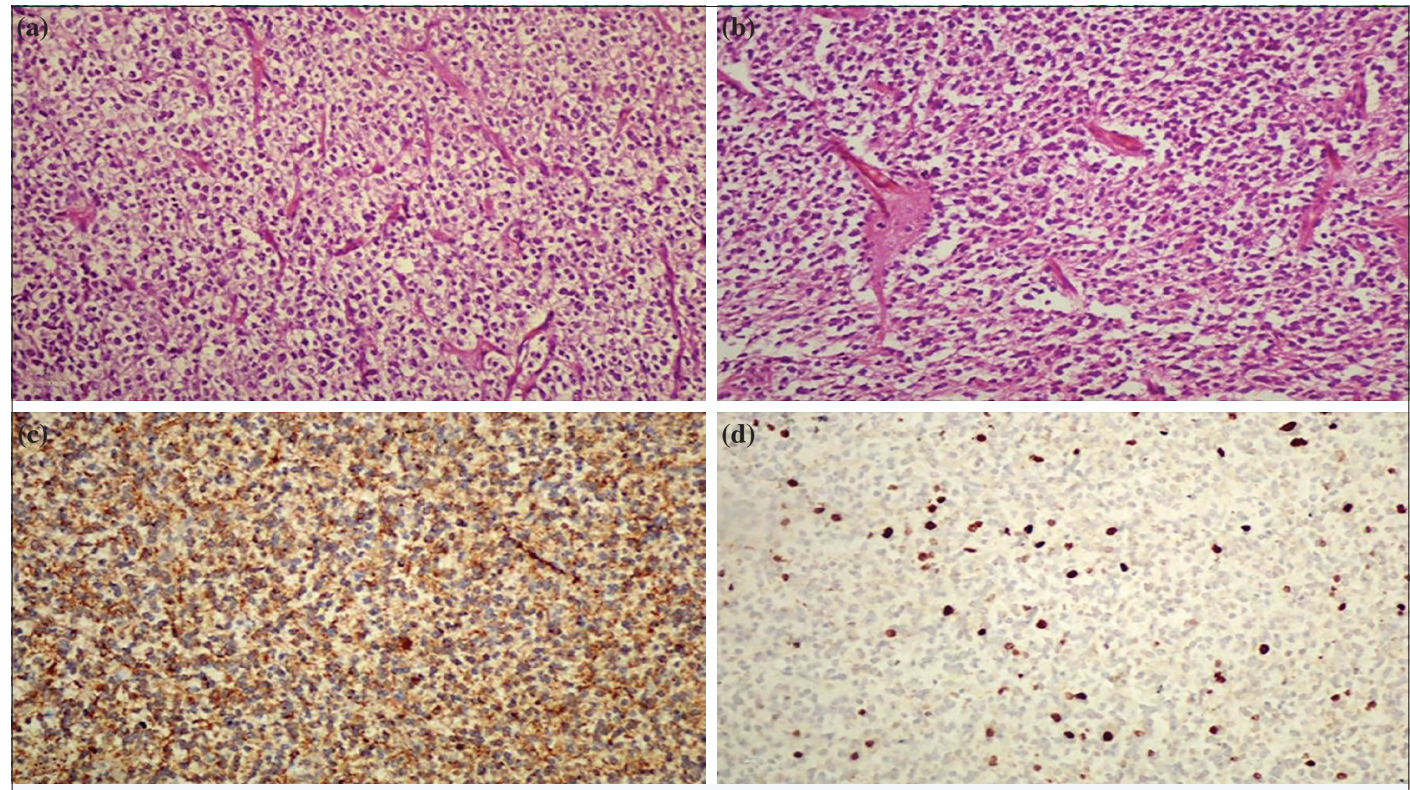

Fig. 1. (a) Neurocytoma, clear cells (H\&E x100). (b) Infiltration including uniform, round cells (H\&E $\mathrm{x} 100)$. (c) Synaptophysin positivity (Immunoperoxidase x100). (d) Nuclear positive reaction in some tumor cells with MIB-1 antibody (Immunoperoxidase x100). 
sification of 2007.[19-21] Extraventricular neurocytoma is a very rare tumor and it is only presented as case report or in small series in the literature. There is very limited data about clinical findings, radiological features, management, or prognosis of extraventricular neurocytoma. The most common location is frontal lobe, followed by temporal lobe, parietal lobe, and occipital lobe, respectively. There is no standard optimum treatment strategy for extraventricular neurocytoma yet. Management of extraventricular neurocytoma is planned under guidance of studies dealing with central neurocytoma.[22] In a series of 49 patients, Xiong et al. compared central neurocytoma cases $(n=35)$ with extraventricularly-located neurocytoma cases $(n=14)$. [23] Their results indicated that central neurocytoma is associated with typical clinical manifestations and histopathological features, whereas extraventricular neurocytoma are associated with higher MIB-1 labeling index levels, higher rates of atypia, higher recurrence rates, shorter recurrence intervals, and worse malignant biological characteristics. In the present series of 6 patients, 1 of 2 extraventricular neurocytomas was inoperable and patient had survival of 42 months; the remaining patient underwent GTR and was still alive and disease-free after 88 months.

Despite low mitotic activity, neurocytoma is a radiosensitive tumor. RT is effective against residual tumor after surgery and helps improve local control after STR. $[4,16,24,25]$ Rades et al. demonstrated in their retrospective series of 358 patients that conventional RT improved local control, particularly after STR.[26] They compared groups of patients who underwent just GTR ( $n=118)$, GTR+postoperative RT ( $n=35)$, just STR $(n=91)$, and STR+postoperative RT $(n=114)$. The rate of atypical neurocytoma was between 3 and $14 \%$ in their series. The 10-year local control rates were $78.3 \%$ in GTR group, $92.3 \%$ in GTR+RT group, $37.7 \%$ in STR group, and $79.4 \%$ in STR+RT group. Similar findings were also published by Schild et al.[27]; local control rate was found to be $100 \%$ for RT-added group, whereas it dropped to $50 \%$ in surgery-only group. The 5 -year survival rates were not statistically significant in the two groups ( $88 \%$ vs $71 \%$ ). Leenstra et al. also recommended postoperative RT in instance of increased mitotic index or after STR.[16] Two groups were retrospectively established after STR for neurocytoma with different irradiation doses (Group A [n=42]; 40-53.6 Gy and Group $B$ [ $n=47] ; 54-62.2 \mathrm{~Gy}$ ] in order to find optimum dose of irradiation. Clearly improved local control rates were achieved for 5 and 10 years in Group B vs Group A: 98\% vs $69 \%$, and $89 \%$ vs $65 \%$, respectively. There is not a sig- nificant difference between groups for 10-year survival rates. Group B had a slight tendency for survival benefit; however, it was not significant.[28] Based on these facts, RT dose of $\geq 54 \mathrm{~Gy}$ is recommended following subtotal resection for neurocytoma. Only 1 patient of 6 in our series received postoperative RT of $<54 \mathrm{~Gy}$. The tumor was located in fourth ventricle with MIB-1 labeling index of $30 \%$. GTR was followed by external RT of $50 \mathrm{~Gy} / 25 \mathrm{fr}$. Intraventricular recurrence was noted 29 months after surgery. Palliative efforts with stereotactic radiosurgery of $6 \mathrm{~Gy}$ x $5 \mathrm{fr}$ were unsuccessful and patient died 2 months after diagnosis of recurrence. Central neurocytoma patient in the present series with MIB-1 labeling index of $<2 \%$ who underwent STR surgery was irradiated with a dose of $60 \mathrm{~Gy} / 30 \mathrm{fr}$ and was still alive after 60 months without any signs of recurrence. Rades et al.[12] found that 3-and 5-year local control rates in patients with atypical central neurocytoma were $73 \%$ and $57 \%$ in total resection group ( $\mathrm{n}=15)$, and $60 \%$ and $31 \%$ in STR group. In the present series, the local control rate was $75 \%$.

Whereas different modalities such as linear accelerator-based radiosurgery and Gamma Knife radiosurgery are used in the treatment of neurocytoma, the majority of studies have focused on the potential offered by Gamma Knife surgery since it was first used by Schild et al.[29] Stereotactic radiosurgery (SRS) is accepted as an equal and even more effective alternative to conventional RT.[25] Rades and Schild[25] compared conventional RT and SRS in 121 patients and did not find any significant difference between STR+conventional RT and STR+SRS groups regarding 5-year local control or 5-year survival rates. Local control of neurocytoma is very important because of the possibility of intracerebral hemorrhage of recurrent typical neurocytoma, malignant degeneration, neurological deterioration, or craniospinal seeding of atypical neurocytoma. [30,31]

Atypical tumor features include necrosis, increased mitotic activity, vascular proliferation, or MIB-1 labeling index $>3 \%$. $[8,13]$ Several studies have revealed that MIB-1 labeling index $>2 \%$ is associated with high recurrence rates. [32-35] Kaur et al. showed that all of the neurocytoma patients with MIB-1 labeling index $>4 \%$ had recurrence in their series. In the present study, 2 of the 3 patients with MIB-1 labeling index $>4 \%$ died.

Serious side effects of radiotherapy in the treatment of neurocytoma, including mortality, have been previously reported.[36] Brain radionecrosis is radiation damage which may result in clinical and dramatic radiological alterations seen months or even years after irradiation.[37] The most common symptoms are psycho- 
motor retardation, seizures, sensorimotor deficit, and speech disturbances.[38] Incidence of brain radionecrosis depends on the dose, fraction, treatment volume, concomitant chemotherapy, anatomical localization of the tumor and RT, and patient characteristics.[39] Pathogenesis of necrosis is strongly associated with increased release of VEGF, serious damage of blood-brain barrier, and dysfunction of endothelial cells. Increased levels of VEGF followed by brain edema and neural demyelination results in tissue necrosis.[40-42] Historically, corticosteroid therapy is the standard treatment for brain radiation necrosis.[43] No benefits have been seen from antithrombotic, anticoagulant, or hyperbaric treatment regimens. [44] Whereas surgery can offer rapid symptomatic improvement, it may result in high-risk complications or neurological deterioration. [45] Today, bevacizumab, a monoclonal VEGF antibody, is used in the treatment of brain radionecrosis. Tye et al.[46] conducted a meta-analysis of 16 studies encompassing a total number of 72 patients diagnosed with CNS radionecrosis between 2007-2012. Median age was 47 yearas and treatment spectrum covered glioblastoma (31\%), anaplastic glioma (14\%), and metastatic brain tumors (15\%). Median interval between completion of RT and initiation of bevacizumab (median 4 cures; median dose $7.5 \mathrm{mg} / \mathrm{kg}$; median interval between cures 2 weeks) was 11 months and the median follow-up after bevacizumab therapy was 8 months. This study revealed significant radiological improvement following bevacizumab treatment and the authors recommended 4 cures of bevacizumab once every 2 weeks with a median dose of $7.5 \mathrm{mg} / \mathrm{kg}$. In the present series, 1 patient developed radionecrosis approximately 3.5 years after completing RT. Surgical excision followed by bevacizumab treatment was performed; however, patient died 2 years after diagnosis of brain radionecrosis.

\section{Conclusion}

The primary treatment for neurocytoma is surgery. Neurocytoma is a grade II brain tumor and RT is not recommended after total resection. Nevertheless, STR of tumor, recurrent disease or atypical tumor features such as high MIB-1 labeling index even after total resection are accepted indicators for irradiation with $>54$ Gy doses. Recent data indicate that the oncologist should pay attention to age, tumor localization, resection type, and MIB-1 proliferation index in making treatment decisions for neurocytoma after surgery.
Conflict of interest: None declared.

\section{References}

1. Hassoun J, Gambarelli D, Grisoli F, Pellet W, Salamon G, Pellissier JF, et al. Central neurocytoma. An electron-microscopic study of two cases. Acta Neuropathol 1982;56(2):151-6.

2. Bertalanffy A, Roessler K, Dietrich W, Aichholzer M, Prayer D, Ertl A, et al. Gamma knife radiosurgery of recurrent central neurocytomas: a preliminary report. J Neurol Neurosurg Psychiatry 2001;70(4):489-93.

3. Chen CL, Shen CC, Wang J, Lu CH, Lee HT. Central neurocytoma: a clinical, radiological and pathological study of nine cases. Clin Neurol Neurosurg 2008;110(2):129-36.

4. Choudhari KA, Kaliaperumal C, Jain A, Sarkar C, Soo MY, Rades D, et al. Central neurocytoma: a multi-disciplinary review. Br J Neurosurg 2009;23(6):585-95.

5. Sharma MC, Deb P, Sharma S, Sarkar C. Neurocytoma: a comprehensive review. Neurosurg Rev 2006;29(4):270-85.

6. Matsunaga S, Shuto T, Suenaga J, Inomori S, Fujino H. Gamma knife radiosurgery for central neurocytomas. Neurol Med Chir (Tokyo) 2010;50(2):107-13.

7. Yarsagil MG, von Ammon K, von Deimling A, Valavanis A, Wichmann W, Wiestler OD. Central neurocytoma: histopathological variants and therapeutic approach. J Neurosurg 1992;76:32-7.

8. Rades D, Schild SE, Fehlauer F. Prognostic value of the MIB-1 labeling index for central neurocytomas. Neurology 2004;62(6):987-9.

9. Hassoun J, Söylemezoglu F, Gambarelli D, FigarellaBranger D, von Ammon K, Kleihues P. Central neurocytoma: a synopsis of clinical and histological features. Brain Pathol 1993;3(3):297-306.

10. Shah T, Jayasundar R, Singh VP, Sarkar C. MRS characterization of central neurocytomas using glycine. NMR Biomed 2011;24(10):1408-13.

11. Rades D, Schild SE. Treatment recommendations for the various subgroups of neurocytomas. J Neurooncol 2006;77(3):305-9.

12. Rades D, Fehlauer F, Schild SE. Treatment of atypical neurocytomas. Cancer 2004;100(4):814-7.

13. Ashkan K, Casey AT, D’Arrigo C, Harkness WF, Thomas DG. Benign central neurocytoma. Cancer 2000;89:1111-20.

14. Kapoor N, Gandhi A, Chaurasia AK. Central neurocytoma in the vermis of the cerebellum. Indian J Pathol Microbiol 2009;52(1):108-9.

15. Vasiljevic A, François P, Loundou A, Fèvre-Montange $\mathrm{M}$, Jouvet A, Roche PH, et al. Prognostic factors in central neurocytomas: a multicenter study of 71 cases. Am J Surg Pathol 2012;36(2):220-7.

16. Leenstra JL, Rodriguez FJ, Frechette CM, Giannini C, 
Stafford SL, Pollock BE, et al. Central neurocytoma: management recommendations based on a 35-year experience. Int J Radiat Oncol Biol Phys 2007;67(4):1145-54.

17. Rades D, Fehlauer F. Treatment options for central neurocytoma. Neurology 2002;59(8):1268-70.

18. Nishio S, Takeshita I, Kaneko Y, Fukui M. Cerebral neurocytoma. A new subset of benign neuronal tumors of the cerebrum. Cancer 1992;70(2):529-37.

19. Brat DJ, Scheithauer BW, Eberhart CG, Burger PC. Extraventricular neurocytomas: pathologic features and clinical outcome. Am J Surg Pathol 2001;25(10):1252-60.

20. Louis DN, Ohgaki H, Wiestler OD, Cavenee WK, Burger PC, Jouvet A, et al. The 2007 WHO classification of tumours of the central nervous system. Acta Neuropathol 2007;114(2):97-109.

21. Sweiss FB, Lee M, Sherman JH. Extraventricular neurocytomas. Neurosurg Clin N Am 2015;26(1):99-104.

22. Kane AJ, Sughrue ME, Rutkowski MJ, Aranda D, Mills SA, Lehil M, et al. Atypia predicting prognosis for intracranial extraventricular neurocytomas. J Neurosurg 2012;116(2):349-54.

23. Xiong Z, Zhang J, Li Z, Jiang J, Han Q, Sun S, et al. A comparative study of intraventricular central neurocytomas and extraventricular neurocytomas. J Neurooncol 2015;121(3):521-9.

24. Anderson RC, Elder JB, Parsa AT, Issacson SR, Sisti MB. Radiosurgery for the treatment of recurrent central neurocytomas. Neurosurgery 2001;48(6):1231-8

25. Rades D, Schild SE. Value of postoperative stereotactic radiosurgery and conventional radiotherapy for incompletely resected typical neurocytomas. Cancer 2006;106(5):1140-3.

26. Rades D, Fehlauer F, Schild S, Lamszus K, Alberti W. Treatment for central neurocytoma: a meta-analysis based on the data of 358 patients. [Article in German] Strahlenther Onkol 2003;179(4):213-8. [Abstract]

27. Schild SE, Scheithauer BW, Haddock MG, Schiff D, Burger PC, Wong WW, et al. Central neurocytomas. Cancer 1997;79(4):790-5.

28. Rades D, Schild SE, Ikezaki K, Fehlauer F. Defining the optimal dose of radiation after incomplete resection of central neurocytomas. Int J Radiat Oncol Biol Phys 2003;55(2):373-7.

29. Park HK, Steven D C. Stereotactic radiosurgery for central neurocytoma: a quantitative systematic review. J Neurooncol 2012;108(1):115-21.

30. Eng DY, DeMonte F, Ginsberg L, Fuller GN, Jaeckle K. Craniospinal dissemination of central neurocytoma. Report of two cases. J Neurosurg 1997;86(3):547-52.

31. Metellus P, Dufour H, Fuentes S, Do L, Figarella-Branger D, Grisoli F. Central neurocytoma revealed by intraventricular hemorrhage. A case report and review of the literature. Neurochirurgie 2001;47(4):445-7.

32. Söylemezoglu F, Scheithauer BW, Esteve J, Kleihues P.
Atypical central neurocytoma. J Neuropathol Exp Neurol 1997;56(5):551-6.

33. Christov C, Adle-Biassette H, Le Guerinel C. Recurrent central neurocytoma with marked increase in MIB-1 labelling index. Br J Neurosurg 1999;13(5):496-9.

34. Kaur G, Kane AJ, Sughrue ME, Oh M, Safaee M, Sun $\mathrm{M}$, et al. MIB-1 labeling index predicts recurrence in intraventricular central neurocytomas. J Clin Neurosci 2013;20(1):89-93.

35. Ogawa Y, Sugawara T, Seki H, Sakuma T. Central neurocytomas with MIB-1 labeling index over 10\% showing rapid tumor growth and dissemination. J Neurooncol 2006;79(2):211-6.

36. Paek SH, Han JH, Kim JW, Park CK, Jung HW, Park $\mathrm{SH}$, et al. Long-term outcome of conventional radiation therapy for central neurocytoma. J Neurooncol 2008;90(1):25-30.

37. Greene-Schloesser D, Robbins ME, Peiffer AM, Shaw EG, Wheeler KT, Chan MD. Radiation-induced brain injury: A review. Front Oncol 2012;2:73.

38. Butler JM, Rapp SR, Shaw EG. Managing the cognitive effects of brain tumor radiation therapy. Curr Treat Options Oncol 2006;7(6):517-23.

39. Minniti G, Clarke E, Lanzetta G, Osti MF, Trasimeni G, Bozzao A, et al. Stereotactic radiosurgery for brain metastases: analysis of outcome and risk of brain radionecrosis. Radiat Oncol 2011;6:48.

40. Nonoguchi N, Miyatake S, Fukumoto M, Furuse M, Hiramatsu R, Kawabata S, et al. The distribution of vascular endothelial growth factor-producing cells in clinical radiation necrosis of the brain: pathological consideration of their potential roles. J Neurooncol 2011;105(2):423-31.

41. Baker DG, Krochak RJ. The response of the microvascular system to radiation: a review. Cancer Invest 1989;7(3):287-94.

42. Remler MP, Marcussen WH, Tiller-Borsich J. The late effects of radiation on the blood brain barrier. Int J Radiat Oncol Biol Phys 1986;12(11):1965-9.

43. Gonzalez J, Kumar AJ, Conrad CA, Levin VA. Effect of bevacizumab on radiation necrosis of the brain. Int J Radiat Oncol Biol Phys 2007;67(2):323-6.

44. Glantz MJ, Burger PC, Friedman AH, Radtke RA, Massey EW, Schold SC Jr. Treatment of radiation-induced nervous system injury with heparin and warfarin. Neurology 1994;44(11):2020-7.

45. McPherson CM, Warnick RE. Results of contemporary surgical management of radiation necrosis using frameless stereotaxis and intraoperative magnetic resonance imaging. J Neurooncol 2004;68(1):41-7.

46. Tye K, Engelhard HH, Slavin KV, Nicholas MK, Chmura SJ, Kwok Y, et al. An analysis of radiation necrosis of the central nervous system treated with bevacizumab. J Neurooncol 2014;117(2):321-7. 